\title{
Validation of the Malay Translation of Brief Core Schema Scale (BCSS-M)
}

\author{
Renee Tan Huey Jing ${ }^{1 *}$, Santhiya A/P Devadas ${ }^{2}$ and Aminah Aishah Binti Yasiman ${ }^{2}$ \\ 1 Psychiatrist, Department of Psychiatry and Mental Health, Hospital Kajang, Malaysia \\ 2 Psychiatry Medical Officer, Department of Psychiatry and Mental Health, Hospital Kajang, Malaysia \\ *Corresponding author: Renee Tan Huey Jing, Psychiatrist, Department of Psychiatry and Mental Health, Hospital \\ Kajang, Jalan Semenyih, Bandar Kajang, 43000, Selangor, Malaysia
}

\section{ARTICLE INFO}

Received: 幽 August 05, 2019

Published: 蔧 August 21, 2019

Citation: Renee Tan Huey J, Santhiya A/P Devadas, Aminah Aishah. Validation of the Malay Translation of Brief Core Schema Scale (BCSS-M). Biomed J Sci \& Tech Res 20(4)-2019. BJSTR. MS.ID.003495.

\begin{abstract}
Negative schema of self and others are closely associated with self-esteem and mood disorder. Identifying negative schema is an important step in effective psychotherapy. Brief Core Schema Scale (BCSS) is a validated and reliable scale to assess general perception about themselves and other people. The original scale is available in English. BCSS was translated to Malaysian language (BCSS-M) and validated in this study. This study involved 279 participants attending psychiatry clinic in a public hospital in Malaysia. Each participant filled up the socio-demographic forms and BCSS. The results of the study showed that BCSS-M demonstrated good internal consistency with Cronbach's $\alpha$ of 0.73 . BCSS-M also exhibited good convergent and discriminant validity. Confirmatory factor analysis showed that it best fit into a 4 factor model. In conclusion, BCSS-M demonstrated good psychometric properties.
\end{abstract}

Keywords: Brief Core Schema Scale; BCSS; Core Beliefs; Negative Self; Negative Others

\section{Introduction}

In accordance to Beck's theory of depression, negative experiences during childhood can contribute to the formation of early maladaptive schema [1]. Early maladaptive schema is defined as a pervasive dysfunctional pattern of emotions, thought and sensation regarding relationship with others [2]. Moment to moment evaluations of self and others influence the state of mind, cognition, memory processes and synthesis of past reactions and thus plays an important role in the formation of schema [3]. Early maladaptive schema leads to intense emotions when triggered by live events in later life. Therefore, individuals with negative core beliefs or negative schemas are at an higher risk for depression. Certain schema-congruent stressful life events during adolescence can activate dysfunctional attitudes which would lead to development and continuation of depression. Vulnerability to anxiety has also been explained in a similar process [4]. Cognitive behavioral therapy has been repeatedly proven to be effective treatment for depression. Nevertheless, there are studies that showed up to $50 \%$ of individuals do not respond fully. [5]. There are some patients especially the chronic cases of depression and anxiety disorders with underlying emotional dysregulation do not respond to it and continue to experience relapses even after treatment [6]. According to Young, some patients may require a more comprehensive treatment approach as they are poor fir for cognitive therapy due to their difficulty in recognising, accessing and altering their cognitions and emotions [6]. Young's schema theory expands the Beckian theory for the treatment of selective treatment resistant cases whose psychological issues are persistent because of the complex characterological underpinnings and chronic emotional dysregulation [7]. An integrative form of psychotherapy known as schema therapy (ST) have been developed and proposed as the recommended treatment approach [8-10]. A research done in Japan studied the relationship of negative and positive evaluation of self, identified using Brief Core Schema Scale, with dysfunctional attitudes in three aspects of life [11]. The study demonstrated that negative self-evaluation was associated with dysfunctional attitude in all three areas i.e. achievement, dependency and self-control [11]. Contrary to common belief, the study indicated positive self-evaluation was actually related to dysfunctional attitude in achievement and selfcontrol [11]. Brief Core Schema Scales (BCSS) is an instrument developed by Fowler et all in order to provide a quick and easily administered measure of four subscales to evaluate the 4 dimensions of negative evaluations 
of self (negative schema) but also positive evaluations of self and positive and negative evaluations of others [12]. BCSS comprises of 24-item 5-point self-reporting scale (0-4), has good reliability and internal consistency, with Cronbach's $\alpha$ coefficients $>.78$ [12] BCSS was translated to Malaysian language which is native language for most patients in Malaysia. The psychometric properties of the Malay translation of BCSS (BCSS-M) was examined in this study to ensure that it is a valid and reliable scale for assessment of core beliefs of patients in Malaysia.

\section{Methodology}

\section{Translation Process}

The Brief Core Schema Scale (BCSS) was translated in 3 phases. In phase 1, the original BCSS in English was translated to Malay by a bilingual language expert who was proficient in both English and Malay to produce BCSS-M-I. Backward translation of BCSS-M-I was done in phase 2 translation by a bilingual language expert who had never seen the original BCSS. Phase 2 translation produced BCSS-MII. BCSS-M-I was compared with BCSS by a team of expert consisting of one psychiatrist, one psychologist and two psychiatry medical officer. Final edition by the team produced BCSS-M-III. BCSS-MIII was pilot tested on 30 participants to produce final version of BCSS-M. Face to face interview of the participants was done during pilot testing during to review participants' understanding and interpretation of the questionnaire. Permission to translate BCSS was obtained from the original author.

\section{Data Collection}

Validation of BCSS-M was done on participants who were attending psychiatry clinic in a public hospital in Malaysia. Participants included in the study were diagnosed with either depressive disorders, bipolar disorder oranxiety disordersaccording to diagnostic criteria of Diagnostic Statistical Manual 5. Participants were able to read and answer in Malay language and were above 18 years of age. Consent was obtained from participants prior to participation in the study. Participants who experienced psychotic symptoms, suicidal intention requiring acute interventions during intake and those who refused participation were excluded from the study. Participants in the study filled up socio-demographic form and BCSS-M. Ethical approval was obtained from the Ethics Committee of the National Medical Research Registry of Malaysia.

\section{Data Analysis}

Statistical analysis was done using IBM SPSS version 22. (IBM, 2018) Descriptive statistics were done to describe demographic characteristics of participants. Internal consistency was based on Cronbach's $\alpha$. Convergent validity of BCSS-M was measured using Pearson's correlations to assess the strength of correlations of items within a domain. Discriminant validity was confirmed when Maximum Shared Variance (MSV) were lower than Average Variance Extracted (AVE) for all the domains. Exploratory factor analysis of BCSS-M was done with factor loading of $>0.5$ for each item. Confirmatory factor analysis with best fitting model analysis was done using Analysis of Moment Structure version 22. Goodness of fit index (GFI) where $\geq 0.8$ was acceptable, comparative fit index (CFI) where $\geq 0.9$ was acceptable, Tucker Lewis index (TLI) where $\geq$ 0.90 was acceptable and root mean square error of approximation (RMSEA) where $\leq 0.08$ was acceptable.

\section{Research Tool-Brief Core Schema Scale (BCSS-M)}

The original BCSS was introduced in 2006 as a self-rated instrument to assess schemata of self and others. [12]. It is a 24 items scale assessing 4 domains i.e. negative self, positive self, negative others and positive others. Individuals were asked to provide a dichotomous answer of YES or NO on whether they agreed with the items stated in each domain. If they answered YES, they were required to rate a five-point rating scale ranging from 0 to 4 indicating whether they belief it slightly to believe it totally. There are six items in each domain. The content of the negativeself component was from self-criticizing words used in Teasdale \& Dent 1987 and Teasdale \& Cox 2001 [12]. The remaining items were designed by the author and team. The BCSS-M is the translation of the original BCSS and has the same number of items as well as scoring scale as the original BCSS. The average duration of administration was 5 minutes. The original BCSS has good reliability and internal consistency with Cronbach's $\alpha$ of 0.78 [12].

\section{Results}

279 participants completed BCSS-M. The socio-demographic characteristics of participants are summarized in Table 1 . There were 206 females and 73 males. The mean age of participants was 31.8. $67.6 \%$ of the participants were working as professionals, $31.5 \%$ were students, $9.6 \%$ were in managerial work, $7.2 \%$ were teachers and $2.9 \%$ were businessman. In the pilot study, all the participants indicated that the wording, sentence construct and semantic properties were clear and appropriate. None of the participants had issues in terms of understanding the wordings or meaning of each item on the scale. All

Participants were able to describe the meaning of the sentences of each item. Thus, no further editing of the BCSS-M was needed. Internal consistency of BCSS-M was measured based on Cronbach's $\alpha$. Cronbach's $\alpha$ of BCSS-M was 0.73. Cronbach's $\alpha$ for each domain are presented in Table 2. The AVE and MSV of each domain were calculated and the results are available in Table 2. MSV for all domains were found to be lower than AVE thus confirming discriminant validity of the scale. Inter factor correlations were summarized in Table 3. Exploratory factor analysis showed all items of the scale had factor loading values ranging from 0.49 to 0.91. (Table 4) Bartlett's test of sphericity was significant $(\mathrm{p}<0.001)$ and Kaiser-Meyer Olkin measure was 0.87 indicating the factor analysis was appropriate. Confirmatory factor analysis indicated BCSS-M best fit into a 4-factor model, $\mathrm{X} 2=337.66, \mathrm{p}<0.001, \mathrm{GFI}=$ $0.87, \mathrm{TLI}=0.90 \geq \mathrm{CFI}=0.92, \mathrm{RMSEA}=0.09$ (Figure 1 ). 
Table 1: Demographic Characteristics of Participants.

\begin{tabular}{|c|c|c|}
\hline Characteristics & Number & Percent (\%) \\
\hline \multicolumn{3}{|c|}{ Age } \\
\hline $18-19$ & 21 & 7.5 \\
\hline $20-29$ & 97 & 34.8 \\
\hline $30-39$ & 111 & 39.8 \\
\hline $40-49$ & 33 & 11.8 \\
\hline $50-59$ & 12 & 4.3 \\
\hline $60-69$ & 3 & 1.1 \\
\hline$>70$ & 2 & 0.7 \\
\hline \multicolumn{3}{|c|}{ Gender } \\
\hline Female & 206 & 73.8 \\
\hline Male & 73 & 26.2 \\
\hline \multicolumn{3}{|c|}{ Highest Education } \\
\hline Primary education & 6 & 2.2 \\
\hline Secondary education & 67 & 24.0 \\
\hline Vocational certificate & 22 & 7.9 \\
\hline Diploma & 16 & 5.7 \\
\hline Degree & 126 & 45.2 \\
\hline Master's degree & 42 & 15.0 \\
\hline \multicolumn{3}{|c|}{ Occupation } \\
\hline Labor & 7 & 2.5 \\
\hline Teacher & 20 & 7.2 \\
\hline Manager & 27 & 9.6 \\
\hline Businessman & 8 & 2.9 \\
\hline Housewife / househusband & 20 & 7.2 \\
\hline Retired & 8 & 2.9 \\
\hline Professionals & 101 & 36.2 \\
\hline Students & 88 & 31.5 \\
\hline
\end{tabular}

Table 2: Internal Consistency and Discriminant Validity of BCSS-M.

\begin{tabular}{|c|c|c|c|c|c|}
\hline Domains of BCSS-M & Mean & Standard Deviation & Cronbach's alpha & MSV & 0.05 \\
\hline Negative Self & 12.09 & 6.45 & 0.89 & 0.05 & 0.58 \\
\hline Positive Self & 6.35 & 7 & 0.9 & 0.2 & 0.61 \\
\hline Negative Others & 6.11 & 5.8 & 0.87 & 0.12 & 0.57 \\
\hline Positive Others & 9.51 & 6.23 & 0.93 & 0.66 \\
\hline
\end{tabular}

MSV: Maximum shared variance

AVE: Average variance extracted

Table 3: Inter-factor correlations of BCSS-M.

\begin{tabular}{|c|c|c|c|c|}
\hline Domains & Negative Self & Positive Self & Negative Others & Positive Others \\
\hline Negative Self & 1 & $-.547^{* *}$ & $.636^{* *}$ & $-.266^{* *}$ \\
\hline Positive Self & $-.547^{* *}$ & 1 & $-.350^{* *}$ & $.400^{* *}$ \\
\hline Negative Others & $.636^{* *}$ & $-.350^{* *}$ & 1 & $-.244^{* *}$ \\
\hline Positive Others & $-.266^{* *}$ & $.400^{* *}$ & $-.244^{* *}$ & 1 \\
\hline
\end{tabular}

** Statistical significance at the 0.01 level. 
Table 4: Factor Loading 4 factor model for BCSS-M.

\begin{tabular}{|c|c|c|c|c|}
\hline & Negative Self & Positive Self & Negative Others & Positive Others \\
\hline Q1 & 0.60 & & & \\
\hline Q2 & 0.74 & & & \\
\hline Q3 & 0.97 & & & \\
\hline Q4 & 0.88 & & & \\
\hline Q5 & 0.70 & & & \\
\hline Q6 & 0.76 & & & \\
\hline Q7 & & 0.80 & & \\
\hline Q8 & & 0.84 & & \\
\hline Q9 & & 0.81 & & \\
\hline Q10 & & 0.75 & & \\
\hline Q11 & & 0.61 & & \\
\hline Q12 & & 0.72 & & \\
\hline Q13 & & & 0.49 & \\
\hline Q14 & & & 0.54 & \\
\hline Q15 & & & 0.72 & \\
\hline Q16 & & & 0.79 & \\
\hline Q17 & & & 0.91 & \\
\hline Q18 & & & 0.84 & \\
\hline Q19 & & & & 0.76 \\
\hline Q20 & & & & 0.69 \\
\hline Q21 & & & & 0.87 \\
\hline Q22 & & & & 0.81 \\
\hline Q23 & & & & 0.83 \\
\hline Q24 & & & & 0.91 \\
\hline
\end{tabular}

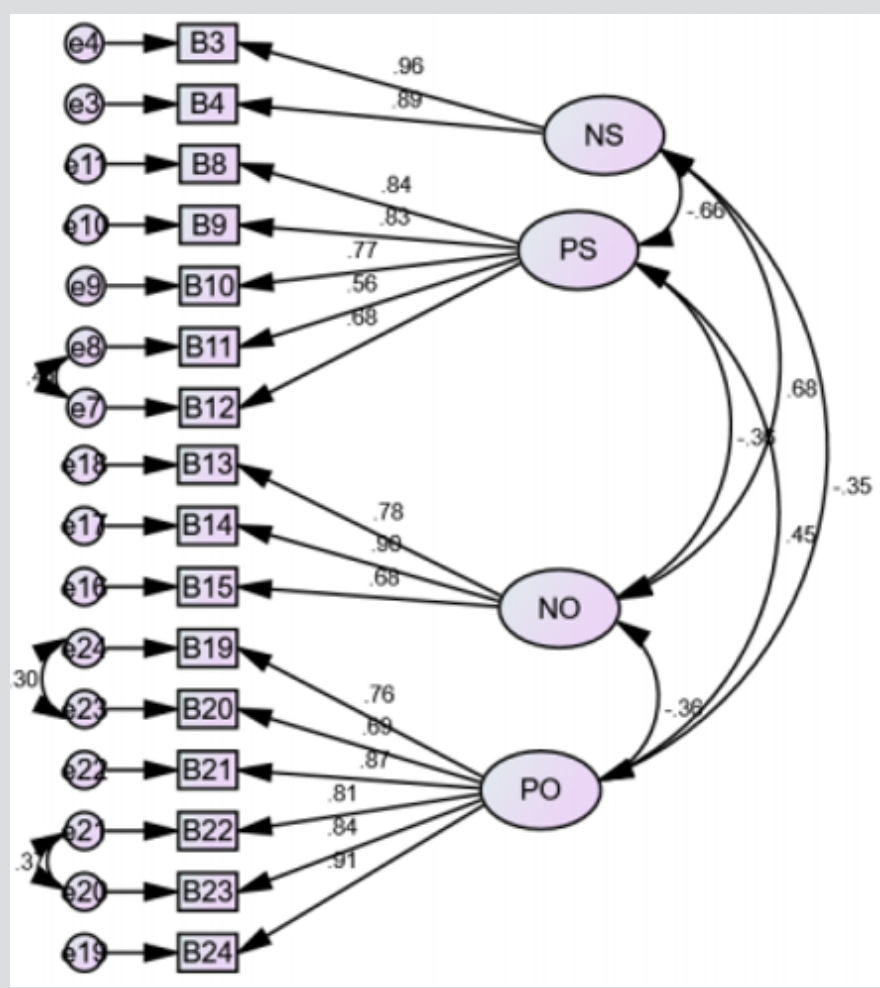

PS: Positive Self; NS: Negative Self; NO: Negative Others; PO: Positive Others

Figure 1: Final Best Fitting 4 factor model of BCSS-M. 


\section{Discussion}

This is a validation study for the Malay translation of Brief Core Schema Scale. There were more female participants as compared to male participants. This is in line with literature on mood disorders whereby it is found to be twice more prevalent in female than male [13-16]. A study on relationship between socio-demographic factors and depression showed that prevalence of depression peaks at age between 20-24 years old and decreases steadily to the lowest level above 70 years old [17]. Similar findings were found in Canadian, Ontario and Australian Health Survey whereby depression rate is higher for 12 to 24 age group in both men and women [18-20]. This was also demonstrated in the socio-demographic characteristics of participants in this study. The study on level of education and mood disorders also found that the lifetime prevalence of depression was highest for those with post-secondary education [17]. This was also found to be the same in participants of this study. This concludes that the participants of this study were representative of the population. The BCSS-M demonstrated good reliability. The Cronbach's $\alpha$ of BCSS-M was 0.73 indicating internal consistency was acceptable. The internal consistency of BCSS-M was found to be similar to that of the original BCSS which has Cronbach's $\alpha$ of 0.78. The Cronbach's $\alpha$ of each domain in BCSS-M was also found to be good i.e. ranging from 0.87 to 0.93 .

The content of BCSS-M was thoroughly reviewed on wording, sentence structure and semantic meaning throughout the translation process by professionals in the field of psychiatry and psychology who were proficient in both Malay and English languages. Face validity was confirmed as all the participants in the study did not had any issues with the contents of BCSS-M during pilot study. BCSS-M has 4 domains i.e. Positive Self, Negative Self, Negative Others and Positive Others. All the Positive self was found to be negatively correlated with Negative Self in this study. It was expected to be so as items of the Positive Self domains were actually opposite statements of items in Negative Self. It was the same for Positive others and Negative Others whereby Positive Others were found to be negatively correlated with Negative Others. However, inter factor correlations for all factors were $<0.85$ indicating they were distinct from each other and no overlapping of variables were found. BCSS-M also exhibited discriminant validity as Maximum Shared Variance (MSV) were found to be lower than Average Variance Extracted for each of the domains. Exploratory factor analysis showed that all items on BCSS-M exhibited relative high factor loadings. However, Item 13 (Other people are hostile) showed a lower factor loading of 0.49 . This result indicated that negative perception of others may be less represented by perception of hostility in others. This may be because in Asian culture, hostility is not something commonly observed in the community. It is due to the presence of collective moral disapproval for hostility or aggression towards others. In a study conducted across Asia, it was found that hostility towards others is only morally and socially justifiable if it was done in order to protect self or others [21]. Therefore, hostility on others was less suitable to represent negative perception of others in Asian population.

\section{Conclusion}

BCSS-M is a reliable and valid scale to assess schemata associated with self and others. Majority of the population in Malaysia are fluent in Malaysian language. As BCSS-M is now available in Malaysian language, it will be convenient for practitioners to use it to assess core beliefs of patients who are fluent in Malaysian language.

\section{Acknowledgement}

The research team wish to thank the Department of Psychiatry and Mental Health Kajang Hospital and all volunteers for the assistance given during the research as well as Dr. David Fowler for granting permission to translate and use the survey instrument. The authors would also like to thank the Director General of Health Malaysia for his permission to publish the article.

\section{Conflict of Interest}

No conflict of interest.

\section{Reference}

1. Beck AT (1987) Cognitive models of depression. Journal of Cognitive Psychotherapy 1(1): 5-37.

2. Tan HJR (2018) Schema Therapy: An Experiential Approach to Dealing with Maladaptive Schema Mode. Biomedical Journal of Scientific \& Technical Research 8(1): 6228-6230.

3. Fowler D, Freeman D, Smith B, Kuipers E, Bebbington P, et al. (2006) The Brief Core Schema Scales (BCSS): Psychometric properties and associations with paranoia and grandiosity in non-clinical and psychosis samples. Psychological Medicine 36(6): 749-759.

4. Hankin BL, Abela JRZ (2005) Development of Psychopathology: A Vulnerability-Stress Perspective. Thousand Oaks, Sage Publications Inc.

5. Carter JD, Mcintosh VV, Jordan J, Porter RJ, Frampton CM, et al. (2013) Psychotherapy for depression: A randomized clinical trial comparing schema therapy and cognitive behavior therapy. Journal of Affective Disorders 151(2): 500-505.

6. Hawke LD, Provencher MD (2011) Schema Theory and Schema Therapy in Mood and Anxiety Disorders: A Review. Journal of Cognitive Psychotherapy 25(4): 257-276.

7. Dadomo H, Grecucci A, Giardini I, Ugolini E, Carmelita A, et al. (2016). Schema Therapy for Emotional Dysregulation: Theoretical Implication and Clinical Applications. Frontiers in Psychology 7.

8. Renner F, Arntz A, Leeuw I, Huibers M (2013) Treatment for Chronic Depression Using Schema Therapy. Clinical Psychology: Science and Practice 20(2): 166-180.

9. Nadort M, Arntz A, Smit JH, Giesen Bloo J, Eikelenboom M, et al. (2009) Implementation of outpatient schema therapy for borderline personality disorder: Study design. BMC Psychiatry 9(1): 64.

10. Taylor CD, Bee P, Haddock G (2017) Does schema therapy change schemas and symptoms? A systematic review across mental health disorders. Psychol Psychother 90(3): 456-479.

11. Otani K, Suzuki A, Matsumoto Y, Shirata T (2017) Relationship of negative and positive core beliefs about the self with dysfunctional attitudes in three aspects of life. Neuropsychiatric Disease and Treatment 13: 25852588.

12. Fowler D, Hodgekins J, Garety P, Freeman D, Kuipers E, et al. (2011) Negative Cognition, Depressed Mood, and Paranoia: A Longitudinal Pathway Analysis Using Structural Equation Modeling. Schizophrenia Bulletin 38(5): 1063-1073. 
13. Seney ML, Sibille E (2014) Sex differences in mood disorders: Perspectives from humans and rodent models. Biology of Sex Differences $5(1)$.

14. Kornstein S, Schatzberg A, Thase M, Yonkers K, Mccullough J, et al. (2000) Gender differences in chronic major and double depression. Journal of Affective Disorders 60(1): 1-11.

15. Kessler RC, Berglund P, Demler O, Jin R, Merikangas KR, et al (2005) Lifetime Prevalence and Age-of-Onset Distributions of DSMIVDisorders in the National Comorbidity Survey Replication. Archives of GeneralPsychiatry 62(6): 593-602.

16. Usall I (2001) Gender differences in mood disorders. A literature reviews. Actas EspPsiquiatr 29(4): 269-274.

17. Akhtar-Danesh N, Landeen J (2007) Relation between depression and sociodemographic factors. International Journal of Mental Health Systems 1(1): 4.

\section{ISSN: 2574-1241}

DOI: 10.26717/BJSTR.2019.20.003495

Renee Tan Huey Jing. Biomed J Sci \& Tech Res

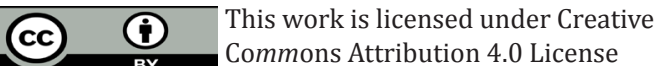

Submission Link: https://biomedres.us/submit-manuscript.php
18. Patten SB (2000) Incidence of major depression in Canada. Canadian Medical Association Journal 163(6): 714-715.

19. (2006) Australian Bureau of Statistics.

20. Offord DR, Boyle MH, Campbell D, Goering P, Lin E, et al. (1996) One-Year Prevalence of Psychiatric Disorder in Ontarians 15 to 64 Years of Age. The Canadian Journal of Psychiatry 41(9): 559-564.

21. Ramirez MJ (2018) Justification of Aggression in Several Asian and European Countries with Different Religious and Cultural Background. International Journal of Behavioural Development 31(1): 9-15.

22. IBM (2018) IBM SPSS Statistics for Windows, Version 22.0. IBM Corp, Armonk, New York, USA.

23. Lyrakos DG (2014) The Validity of Young Schema Questionnaire $3^{\text {rd }}$ Version and the Schema Mode Inventory $2^{\text {nd }}$ Version on the Greek Population. Psychology 5(5): 461-477.

$\begin{array}{ll}\text { BIOMEDICAL } & \text { Assets of Publishing with us } \\ \text { RESEARCHES } & \text { - Global archiving of articles } \\ & \text { - Immediate, unrestricted online access } \\ & \text { - Rigorous Peer Review Process } \\ \end{array}$

